\title{
Self-transcendence facilitates meaning-making and flow: Evidence from a pilot experimental study
}

\author{
Evgeny N. Osin ${ }^{\mathrm{a}, \mathrm{b}^{*}}$, Anna V. Malyutina ${ }^{\mathrm{b}, \mathrm{c}}$, Natalia V. Kosheleva ${ }^{\mathrm{a}}$ \\ ${ }^{a}$ International Laboratory of Positive Psychology of Personality and Motivation, National \\ Research University Higher School of Economics, Moscow, Russia \\ ${ }^{\mathrm{b}}$ Department of Psychology, National Research University Higher School of Economics, Moscow, \\ Russia
}

' X5 Retail Group, Moscow, Russia

* Corresponding author. E-mail: evgeny.n.osin@gmail.com

We review the psychological theory of flow and focus on the notion of the autotelic personality, arguing that self-transcendence (understood within the existential tradition of Frankl and Längle as the individual's ability to establish inner relationships with values) can be viewed as a personality disposition conducive to flow experience. The study aimed to investigate the effects of situational task meaning and dispositional self-transcendence on productivity and flow experience. We present a pilot quasi-experimental study conducted in a student sample $(\mathrm{N}=82)$ Students were asked to work in small-group settings on a creative task, which consisted in finding solutions to a social problem. Each group was randomly assigned to an instruction presenting the problem as happening either in a distant country (low-meaning) or in their home country (high-meaning condition). The outcome variables were measures of flow, perceived meaning of the task, and satisfaction with time spent working. The solutions generated by the students were rated by three experts. The experimental manipulation had a main effect on the quality of the resulting solutions, but not on the subjective experience of the participants. A number of significant interaction effects were found, indicating that the associations of self-transcendence with experiential outcomes tended to be linear under the low-meaning condition, but curvilinear under the high-meaning condition. The findings suggest that self-transcendence is particularly beneficial to flow in situations with unclear meaning, but very high levels of self-transcendence may hinder flow in highly meaningful situations. Overall, the findings suggest that self-transcendence can be considered as a disposition of the autotelic personality.

Keywords: flow experience, self-transcendence, personal meaning, autotelic personality 


\section{Introduction}

\section{The concept of flow}

Engagement with the world is the essence of human life. By engaging we become motivated, experience meaning, exercise our strengths, and achieve personal growth. Among theories describing optimal experiences of engagement, the flow theory has generated the most research attention. Csikszentmihalyi (1990) describes flow as the experience associated with an autotelic (intrinsically enjoyable, self-rewarding) activity characterized by intense and effortless concentration on the task at hand, merging of action and awareness, a sense of control, loss of selfconsciousness, altered sense of time, and continuous enjoyment. Flow experiences have been studied in the context of various everyday activities, including work, study, sports and active leisure (rock climbing, sailing), listening to or performing music, dancing, sex, creative writing, and even household chores, like ironing clothes or driving a car (Nakamura \& Csikszentmihalyi, 2000).

Empirical studies of flow states began by using qualitative interviews. Later on, various structured paper-and-pencil questionnaire measures were developed, including the Experience Sampling Method (ESM), which made it possible to study flow experiences in the context of everyday flow activities (for reviews, see Nakamura \& Csikszentmihalyi, 2000; Delle Fave, 2014). More recently, researchers have begun to use experimental flow-inducing interventions. Summarizing the results of these studies, Moller, Meier, and Wall (2010) review contextual factors that have been shown to be conducive to flow experience in experimental studies. They note that a balance between challenges and skills, even though efficient in inducing flow, may not be a sufficient condition for flow. Among other factors that contribute to creating a flow experience are task instrumentality (extrinsic utility), which facilitates flow even under a suboptimal balance of challenges and skills; clarity of goals and feedback; autonomy support at the context level; and minimization of distraction. Minimization of distraction involves removing any stimuli that increase reflective self-awareness, which includes other people and the experimenter (Moller, Meier, \& Wall, 2010). However, the flow-inducing activity itself may involve interpersonal interaction. Walker (2010) has shown that social flow, particularly in highly interdependent teams, is more enjoyable to participants than is flow in solitary or non-interdependent social settings.

Because flow is an emergent phenomenon of person-environment interaction, its level is dependent not only on situational variables, but also on personality characteristics. The latter have, until very recently, received comparatively little research attention.

\section{The autotelic personality}

From its beginning, flow theory and research have focused mostly on the phenomenology of flow. Csikszentmihalyi and colleagues found that although "the capacity to experience flow appears to be nearly universal," people exhibit a large degree of individual differences both in the frequency and the quality of flow they tend to report in the same situations (Nakamura \& Csikszentmihalyi, 2000, p. 93).

In order to explain these differences, Csikszentmihalyi introduced the concept of the autotelic personality, originally defined as a person "who generally does things 
for their own sake, rather than in order to achieve some later external goal" (Csikszentmihalyi, 1997, p. 117). Later he suggested that this type of personality is characterized by metaskills, or "competencies that enable the individual to enter flow and stay in it," including "a general curiosity and interest in life, persistence, and low self-centeredness" (Nakamura \& Csikszentmihalyi, 2000, p. 93). These characteristics facilitate emergent motivation, which arises in the process of dynamic interaction between the person and the environment.

Initially, autotelic personality was operationalized using ESM data as time spent in flow or as subjective preference for high-challenge, high-skill situations; attempts to operationalize it using a combination of existing measures of personality traits that reflect receptivity and achievement orientation have also been made (Nakamura \& Csikszentmihalyi, 2000).

More recent studies focus on personality traits that moderate the associations between the objective features of situations and the resulting flow experience (for reviews, see Moller, Meier, \& Wall, 2010; Delle Fave, 2014). Abuhamdeh and Csikszentmihalyi (2009) found that high intrinsic motivation orientation (IMO) was associated with higher enjoyment of high-challenge games in chess players. They also found that the association between challenge and enjoyment was curvilinear in individuals with high IMO, but linear in those with low IMO.

Among other personality dispositions associated with higher flow are achievement motivation (Eisenberger et al., 2005; Engeser \& Rheinberg, 2008), internal locus of control (Keller \& Blomann, 2008), action orientation (Keller \& Bless, 2008), self-efficacy (Bassi, Steca, Delle Fave, \& Caprara, 2007), optimism, self-esteem, and extraversion (Schmidt, Shernoff, \& Csikszentmihalyi, 2007). These dispositions promote flow either by facilitating sustained task engagement (action orientation) or by making a person more sensitive to the challenge/skill balance (achievement motivation, internal locus of control).

Though a number of trait-level moderators of flow have been found, more research into individual differences in flow quality and flow proneness is needed to create a consistent theoretical model of the autotelic personality.

\section{Self-transcendence: Definitions and measures}

One personality disposition that seems to be particularly relevant to flow research is self-transcendence. This concept was introduced in existential psychology, first and foremost, by Frankl (1966). He understood self-transcendence as "a constitutive characteristic of being human that always points, and is directed, to something other than itself.... Actually, being human profoundly means to be open to the world, a world, that is, which is replete with other beings to encounter and with meanings to fulfill" (Frankl, 1966, p. 97).

For Frankl, self-transcendence involves being motivated by meaning, which can only be found, experienced, or created in the process of interaction with the world. Similar to the perception of a gestalt, the perception of meaning "boils down to becoming aware of a possibility against the background of reality ... becoming aware of what can be done about a given situation" (Frankl, 1992, p. 145). This cognitive restructuring of a situation happens due to the activity of conscience, which evaluates each situation in the light of our hierarchy of values that are not conscious 
constructs, but rather are inherent in human nature. However, the perception of the possibility of meaning is only a first step towards creating meaning in life, which emerges as a result of active doing, experiencing, or position-taking.

In a similar vein, May used the term "self-transcendence" to refer to the capacity to transcend the immediate situation "and to assess and guide one's self by an infinite variety of possibilities" (May, 1958, p. 74). The capacity for self-transcendence, for May, is part of the ontological nature of being human and is the basis for human freedom. Both Frankl and May emphasize the ontological rather than the psychological aspect of self-transcendence, seeing it as a property of human existence, rather than an individual difference construct. In contrast, Maslow introduced the concept of self-transcendence in his later theory of metamotivation, or growth motivation (Maslow, 1971). He suggested that self-actualization culminates in seeking to further some cause beyond the self and in being motivated by universal values (meta-needs), providing a basis for viewing self-transcendence as a disposition.

This early theorizing led to adoption of the construct of self-transcendence in empirical research that aimed to measure differences in the extent to which individuals exercise this capacity in everyday situations. Within the context of Frankl's theory, Längle and colleagues (2003) operationalized Längle's model of existential dialogue with the world, which involves four steps: self-distancing or self-detachment (directing oneself towards the world in order to see the possibilities), selftranscendence (perceiving the value of each possibility), freedom (making a decision in favor of a possibility), and responsibility (carrying out this decision). In this model, self-transcendence is seen a step when "the subject gets to understand the qualitative relationships between the objects and him/herself. A hierarchy of the more valuable goals (contents, possibilities) is developed. This is based on the recognition of one's emotional and evaluative reaction to perceived and imagined objects" (Längle et al., 2003, p. 138). Thus, self-transcendence is seen as a cognitive integrative process, which, however, is not focused on the self or on emotional reactions, but on the situation in its relationship to the self, which is being clarified and experienced. Längle and colleagues (Längle, Orgler, \& Kundi, 2003) developed a 46-item instrument, the Existence Scale, measuring self-distancing, self-transcendence, freedom, and responsibility as dispositions, or "personal competencies for existence" (p. 158). The scales showed satisfactory internal consistency and retest stability. Predictably, they were positively associated with meaning, negatively associated with depression and neuroticism, and unrelated to extraversion.

Other empirical approaches to self-transcendence include Cloninger's psychobiological model of personality (Cloninger, 1987), which defines character traits as individual differences in self-object relationships, including self-transcendence. The operationalization of self-transcendence in the Temperament and Character Inventory (Cloninger, 1987) is comprised of three facets: 1) self-forgetful vs. selfconscious experience; 2) transpersonal identification vs. self-differentiation; 3) spiritual acceptance vs. rational materialism. Within nursing theory, Reed (1991) defined self-transcendence as the ability to expand the boundaries of the self and to experience intrapersonal, interpersonal, and transpersonal connectedness. Measures of self-transcendence understood as a shift of focus from centeredness on self and material interests towards a cosmic and transcendent view of life were developed within gerontology (see Garcia-Romeu [2010]). 


\section{Self-transcendence and flow: Meaning as a link}

From these different conceptualizations of self-transcendence, Längle's approach seems to be particularly relevant to flow research, because it describes self-transcendence as an individual disposition for cognitive activity that clarifies the relationship between the world (in a given situation) and the self, forming a basis for emergent motivation. In Frankl's (1992) theory, like other existential approaches, meaning is understood as a perceived possible relationship with the world, a direction which motivates the individual to act. However, in order for an experience of a meaningful life (existential fulfilment) to emerge, action guided by meaning is essential.

This interactionistic approach to meaning becomes a challenge for empirical psychology (Leontiev, 2013), where meaning is often construed within an isolatedsubject paradigm, in terms of subjective experience. However, we deem this view of meaning too simplistic, because ignoring the context of relationships with the world (and oneself) that form the essence of meaning makes it impossible to study the role of situational context and personality activity in the emergence of meaning and its motivating power. Following Leontiev (2013), we call for a multifaceted theoretical view of meaning.

In Csikszentmihalyi's flow theory, meaning is also defined phenomenologically, in terms of subjective experience related to a certain activity or object. However, Csikszentmihalyi and Nakamura emphasize the emergent nature of meaning: "as a person is drawn onward by enjoyable interaction with an object, the meaning of the relationship gradually deepens" (Csikszentmihalyi \& Nakamura, 2003, p. 95). They associate this phenomenon with a specific form of subjective meaning, "the felt significance of an enjoyed relationship to a domain" (p. 98). In order for a flow activity to become a "vital engagement" (the basis of a lifetime career, a calling), the activity needs to be meaningful, and its meaning for an individual is enriched by a community of people who practice it (Csikszentmihalyi \& Nakamura, 2003).

Frankl (1992) emphasizes that pleasure is only a byproduct of the pursuit of meaning, rather than its motivating power, and fulfilling life is achieved by following the direction of meaning, even if this process involves effort and suffering. Csikszentmihalyi \& Nakamura (2003) believe that lifetime engagement is fostered by a coincidence of enjoyment and meaning in the same flow activity, which, even though it takes effort, is experienced as effortless. Frankl's view, however, does not conflict with that of flow theory, given the different historical context of these two theories: "meaning is available in spite of - nay, even through - suffering, provided ... that the suffering is unavoidable. If it is avoidable, the meaningful thing to do is to remove its cause" (Frankl, 1992, p. 148).

A more general understanding of meaning as context-relatedness, proposed by Leontiev (2013), is helpful to understand why an activity becomes meaningful: "the meaning of action is derived from its goal, the meaning of goal from its motivation, the meaning of motive from life at large, the meaning of life from some sources that embrace our life as a subordinate element" (p. 466). In light of this understanding, the positive effect of task instrumentality on flow discovered by Engeser and Rheinberg (2008) can be seen as the effect of meaning that the flow activity gains within a larger context of personal motives. 
Based on these theories, we hypothesized that the meaning of an activity facilitates flow and that the disposition to self-transcendence is a personality resource that helps individuals to discover meaning in different situations and to experience flow. Some support for the second hypothesis is provided by Teng (2011), who found a weak positive association $(\mathrm{r}=.14)$ between measures of self-transcendence and dispositional flow in a sample of online gamers. In order to explore these hypotheses at the situational level, we conducted a pilot quasi-experimental study, studying the effects of situational meaning (operationalized as the relationship of a task situation to an individual's life) and dispositional self-transcendence (as a subject variable).

We aimed to explore three research questions:

1. Are highly self-transcendent people more likely to experience flow when there is an opportunity to engage in a potentially meaningful activity?

2. Is self-transcendence associated with higher experience of meaning of a task and higher task productivity?

3. Are the effects of self-transcendence on experiential outcomes (perceived meaning, flow) contingent on the extent of task meaning within the task situation?

\section{Methods}

\section{Participants}

The participants were 82 undergraduate psychology students (first and second year) from a Moscow-based university, including 20 males and 62 females aged from 16 to 20 (median $=18$ ). Out of 140 students registered for the course, 112 volunteered for the study and completed the pre-test; 82 of these were present at the experimental session.

\section{Instruments}

Activity Flow Scale (AFS: Payne, Jackson, Noh, \& Stine-Morrow, 2011; translated into Russian by Author 1 and Author 2 for the present study), a 26-item instrument using a 5-point response scale. It includes nine subscales measuring specific aspects of flow experience: spontaneity, clarity of goals, concentration, feedback, balance of challenges and skills, altered sense of time, perceived control, loss of selfconsciousness, and intrinsic enjoyment.

Brief Flow Scale (BFS: Collins, Sarkisian, Winner, 2009; translated into Russian by Author 2 for the present study) is a 5-item instrument that uses a binary response scale. It is a general index of flow, with items tapping into concentration on task, loss of self-consciousness, and sense of control. The internal consistency coefficients for this and the following measures are given in Table 2.

Existence Scale (Längle, Orgler, \& Kundi, 2003; Russian version: Mainina, 2009). This instrument includes 46 items evaluated on a 6-point response scale, grouped into four scales corresponding to personality dispositions relevant to the four stages of existential dialogue with the world described in Längle's model: SelfDistancing (SD), Self-Transcendence (ST), Freedom (F), and Responsibility (V). 
The Self-Transcendence scale includes 14 items tapping into one's capacity to relate to the world and perceive the significance of things and situations, e.g.: "I like to form my own opinions"; "I have a hard time realizing what relevance things have for my life" (reverse-scored); "Ultimately I can't relate to many things I have to deal with" (reverse-scored).

Perceived Quality of Time Scale (PQT: Leontiev, in preparation), a 15-item instrument. The respondents are asked to retrospectively evaluate their experience associated with a period of time (in the present study, the time they spent doing the experimental task), using a set of 7-point bipolar rating scales anchored by antonymous adjectives (e.g., "full of life ... lifeless," "colorless ... bright," "special ... ordinary").

Situational Experienced Meaning scale (SEM: Leontiev, in preparation), a 21item instrument. The respondents are asked to rate retrospectively an activity they were engaged in (in our case, participation in the experimental task), using a set of 7-point bipolar scales anchored by antonymous adjectives describing experiential correlates of a meaningful activity (e.g., "boring ... interesting," "useful ... useless," "purposeful ... pointless").

\section{Design and procedure}

The study used a quasi-experimental design with dispositional self-transcendence and situational meaning (two levels) as independent variables. The dependent variables were task productivity and subjective experience (indicators of flow, experienced meaning, and life quality). The study involved three stages:

1. Pre-test. Students completed the Existence Scale 2 weeks before the experiment.

2. Intervention. The students were approached during their practical sessions (part of the creative thinking module of the general psychology course), which take place in groups of 25-30 students. The students were asked to form small groups (three to four individuals in each), in order to "to participate in a short creative thinking task".

The meaning condition was operationalized as two types of instructional leaflets (presented below in the supplementary information), one of which was given to each group on a random basis. The instructions asked students to use their psychology expertise in a creative task consisting in finding solutions to the social problem of firearm abuse by police officers. In the low-meaning condition, the problem was presented as taking place in African countries; in the high-meaning condition, it was presented as taking place in the students' home country.

The students were asked to work for 15 to 20 minutes and to write down as many realistic ideas as possible on a sheet of paper provided with the leaflet. The experimenter (AM) remained present in the room while the students worked, and reminded them when they had 5 minutes remaining to finish their work after 15 minutes had expired.

3. Post-test. Immediately after they finished work, the students were asked to return to their individual seats and to complete a set of questionnaires measuring their subjective experience of working on the task. They were also asked to indicate the number of minutes that the time working on the task felt like. 
Three experts with a graduate degree in psychology were asked to rate the originality of each solution on a 5-point scale (from 1 - "not original at all" to 5 "highly original") and its practicability on a 3-point scale $(1-$ definitely possible to implement, $0-$ not sure, $-1-$ definitely not practicable). The experts worked independently and were not provided with the information about the type of instructions received by each group.

\section{Results}

\section{Experience measures: Structure and reliability}

The reliability of the complete BFS was fairly low $(\alpha=.65)$. Based on item analysis, one item (\#3, the only one tapping into sense of control) was found to have a nonsignificant correlation with the scale $(r=.05)$ and was excluded from the scale, which improved the reliability ( $\alpha=.76)$.

The structure of the AFS was evaluated using exploratory and confirmatory factor analysis (Mplus 7.11, MLM estimator). The theoretical 9-scale measurement model for 26 items with one additional covariance between items 7 and 9 (similarly worded and belonging to the same subscale) fit the data fairly well $\left(\chi^{2}=330.49\right.$, $\mathrm{df}=262, \mathrm{p}=.003$; CFI $=.939$; RMSEA $=.056,90 \%$ CI [.035-.074]). All the factor loadings were statistically significant and meaningful (standardized $\lambda$ in the .44-.94 range). The internal consistency coefficients for the subscales (Cronbach's a) ranged from .63 to .90 .

Table 1. Reliability and factor structure of the AFS subscales $(\mathrm{N}=82)$

\begin{tabular}{lcrrrrr}
\hline \multirow{2}{*}{ AFS subscale } & N & Cronbach's & $\begin{array}{c}\text { 1-factor } \\
\text { model }\end{array}$ & \multicolumn{3}{c}{ 3-factor model } \\
\cline { 6 - 8 } & items & $\boldsymbol{\alpha}$ & F1 & F1 & F2 & \multicolumn{1}{c}{ F3 } \\
\hline Spontaneity & 3 & .82 & -.28 & -.08 & .63 & .59 \\
Clear goals & 3 & .89 & .78 & .74 & -.23 & .04 \\
Concentration on task & 4 & .85 & .79 & .77 & -.08 & -.15 \\
Feedback & 2 & .74 & .63 & .67 & .17 & -.07 \\
Balance of challenges and skills & 3 & .63 & .65 & .55 & -.48 & .10 \\
Altered sense of time & 3 & .85 & -.02 & .02 & -.19 & .90 \\
Sense of control & 2 & .90 & .67 & .76 & .30 & .11 \\
Loss of self-consciousness & 3 & .90 & -.05 & .12 & .80 & -.18 \\
Intrinsic enjoyment & 3 & .86 & .73 & .74 & -.02 & .03 \\
\% of variance explained & & & 34.59 & 34.59 & 15.86 & 13.66 \\
\hline
\end{tabular}

We used principal components analysis with Oblimin rotation to find out whether subscale scores would form a single index of flow. The internal consistency coefficients of the AFS subscales and the resulting factor structures are presented in the supplementary information. Three subscales (spontaneity, altered sense of time, and social evaluation) exhibited low loadings on the single factor. Based on the scree plot, we studied a 3 -factor model explaining $64 \%$ of the variance (see Table 
1). Six out of nine flow subscales loaded on the first factor. The second factor was interpreted as the social evaluation/spontaneity dimension, reflecting individual differences in reaction to work in a group setting. The time subscale formed a separate, third dimension. Because the structure could reflect the specific features of the experimental situation (group setting and the presence of an external time limit), we used a sum of the six subscales with high loadings on the first factor to form a total flow index, which was moderately correlated with the BFS (see Table 2).

Because of the limited data on the structure of the PQT and SEM scales, we studied it using principal components analysis. For the PQT scale, we chose a single-factor model explaining $43.6 \%$ of the variance (factor loadings in the $.34-.82$ range for all items) and interpreted as positive vs. negative evaluation of the time that has passed. The SEM scale turned out to be heterogeneous, and we chose one of its dimensions most closely related to the theoretical definition of meaning, including 7 items: "important ... unimportant", "related to someone ... not related to anyone", "purposeful ... aimless", "fruitful ... fruitless", "related to life ... excluded from life", "consequential ... inconsequential", "necessary ... unneeded".

Table 2. Correlations among the study variables (combined sample, $\mathrm{N}=82$ )

\begin{tabular}{ccccccccc}
\hline & $\alpha$ & SD & ST & F & V & BFS & AFS & SEM \\
\hline SD & .67 & & & & & & & \\
ST & .80 & $.53^{* * *}$ & & & & & & \\
F & .76 & $.46^{* * *}$ & $.56^{* * *}$ & & & & & \\
V & .79 & $.55^{* * *}$ & $.45^{* * *}$ & $.61^{* * *}$ & & & & \\
BFS & $.76^{\text {x }}$ & -.11 & .08 & .08 & -.07 & & & \\
AFS & .90 & .04 & $.25^{*}$ & $.22^{*}$ & .11 & $.59^{* * *}$ & & \\
SEM & .81 & .14 & $.26^{*}$ & .06 & .07 & $.33^{* *}$ & $.65^{* * *}$ & \\
PQT & .90 & .15 & .13 & .11 & .05 & $.44^{* * *}$ & $.70^{* * *}$ & $.65^{* * *}$ \\
\hline
\end{tabular}

Note: ${ }^{\mathrm{x}}$ - based on tetrachoric correlation matrix; ${ }^{* *}-\mathrm{p}<.001$, $^{* *}-\mathrm{p}<.01,{ }^{*}-\mathrm{p}<.05$; SD - SelfDistancing, ST - Self-Transcendence, F - Freedom, V - Responsibility, BFS — Brief Flow Scale, AFS - Activity Flow Scale, SEM - Situational Experienced Meaning, PQT - Perceived Quality of Time.

\section{Task productivity characteristics}

There were 24 small groups, which produced 254 solutions. The correlations among the ratings of the solutions by the three experts were moderate $(\mathrm{r}$ in the $.43-.63$ range) and the reliability (Cronbach's $\alpha$ ) of the combined score from the three experts was sufficient for both originality $(\alpha=.78)$ and practicability $(\alpha=.76)$.

There were no significant differences between the average number of solutions per group produced by groups working under the high-meaning $(\mathrm{N}=13)$ and lowmeaning $(\mathrm{N}=11)$ conditions (Cohen's $\mathrm{d}=.45, \mathrm{t}(22)=1.01)$. However, individual solutions produced under the meaningful condition $(\mathrm{N}=126)$ were rated by the experts as more realistic and practicable $(\mathrm{d}=.43, \mathrm{t}(252)=3.41, \mathrm{p}<.001)$, although less original $(\mathrm{d}=.32, \mathrm{t}(252)=2.51, \mathrm{p}<.05)$, compared to the solutions generated under the low-meaning condition $(\mathrm{N}=128)$. 


\section{The effects of self-transcendence and task meaning}

The correlations among the study variables for the two experimental conditions separately are presented in Table 3 . In the low-meaning condition, existential personality indicators exhibited positive associations with the AFS, situational meaning, and perceived quality of time. In the high-meaning condition, the only such association was a negative association of perceived quality of time with responsibility, suggesting that more responsible individuals tended to enjoy the process less.

Table 3. Correlations of the study variables in the high-meaning condition $(\mathrm{N}=40$, above the diagonal) and the low-meaning condition $(\mathrm{N}=42$, below the diagonal)

\begin{tabular}{|c|c|c|c|c|c|c|c|c|}
\hline & SD & ST & F & $\mathrm{V}$ & BFS & AFS & SEM & PQT \\
\hline SD & - & $.55^{\star * *}$ & $.52^{\star \star \star}$ & $.52^{\star \star *}$ & -.22 & -.23 & -.16 & -.22 \\
\hline ST & $.62^{\star x *}$ & - & $.63^{* * *}$ & $.58^{\star * *}$ & .01 & .13 & .07 & -.17 \\
\hline $\mathrm{F}$ & $.47^{* * *}$ & $.62^{* * *}$ & - & $.61^{* * *}$ & -.02 & .03 & -.11 & -.20 \\
\hline V & $.56^{* * *}$ & $.41^{\star *}$ & $.66^{* * *}$ & - & -.06 & -.06 & -.19 & $-.33^{*}$ \\
\hline BFS & -.05 & .11 & .12 & -.06 & - & $.68^{\star * *}$ & .26 & $.42^{* \star}$ \\
\hline AFS & .17 & $.32^{*}$ & $.35^{\star}$ & .20 & $.52^{\star * *}$ & - & $.53^{* * *}$ & $.49^{* *}$ \\
\hline SEM & $.31^{\star}$ & $.42^{* *}$ & .23 & .24 & $.38^{\star}$ & $.74^{* * *}$ & - & $.55^{\star * *}$ \\
\hline PQT & $.31^{\star}$ & $.34^{*}$ & $.32^{*}$ & .25 & $.44^{* *}$ & $.81^{\star * *}$ & $.73^{\star * *}$ & - \\
\hline
\end{tabular}

Note: ${ }^{* *} \mathrm{p}<.001,{ }^{* *} \mathrm{p}<.01,{ }^{*} \mathrm{p}<.05 . \mathrm{SD}-$ Self-Distancing, ST - Self-Transcendence, F - Freedom, V - Responsibility, BFS - Brief Flow Scale, AFS - Activity Flow Scale, SEM - Situational Experienced Meaning, PQT - Perceived Quality of Time.

In order to evaluate the combined effects of self-transcendence and experimental manipulation on the dependent variables, we applied hierarchical multiple regression. Based on investigation of scatterplots, we decided to investigate the possible non-linearity of the associations by including a quadratic term. Effect coding was used for the meaning condition (-1 for low-meaning, 1 for high-meaning). Self-transcendence scores were centered. First-order and second-order interaction terms were created by multiplying the self-transcendence scores by the meaning condition variable. First-order interaction term, quadratic term for self-transcendence, and quadratic interaction term were entered at steps 2,3 , and 4, respectively. The results of hierarchical multiple regression analyses are presented in Table 3 . We followed by testing simple effects for linear and quadratic models for each of the two conditions separately (the detailed results are given in the supporting information).

The results indicate that the experimental manipulation of task meaning had no main effect on the characteristics of the resulting subjective experience. Selftranscendence was significantly positively associated with clarity of goals, perceived balance of challenges and skills, and freedom from social evaluation, suggesting that self-transcendent individuals find it easier to perceive the task structure in a way that is conducive to flow and are less prone to engage in self-focused processing. Self-transcendence was also marginally positively associated with the subjective experience of meaning and the overall index of flow. 


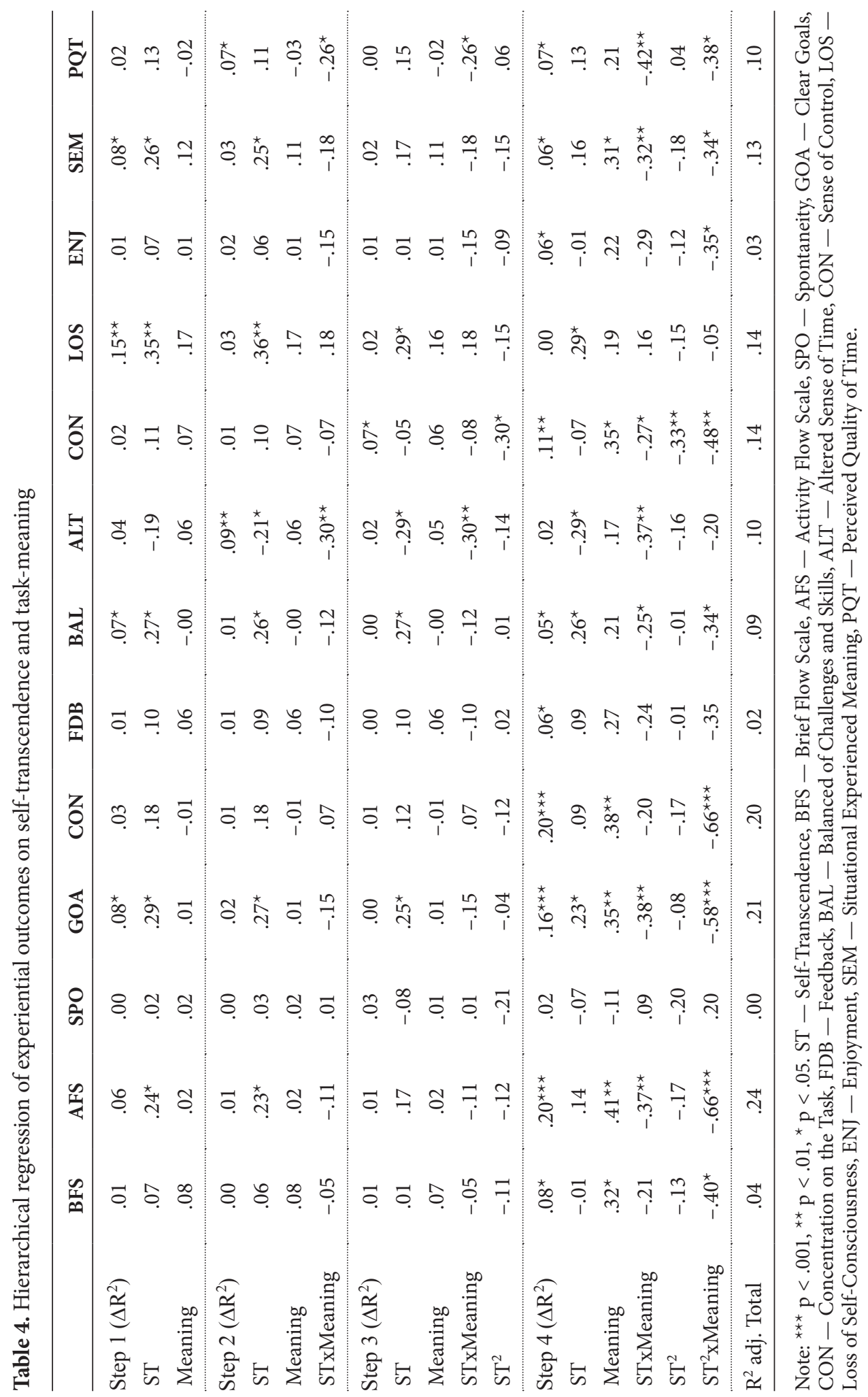


There were significant negative interaction effects between self-transcendence and task meaning for the altered sense of time subscale of the AFS and for the Perceived Quality of Time scale. These effects indicate that in the low-meaning condition, individuals with higher self-transcendence were more likely to experience altered sense of time and enjoy the time spent working on the task; however, in the high-meaning condition, self-transcendent individuals were not as likely to get absorbed in the process and enjoy it. The addition of a quadratic term for selftranscendence at step 3 was only significant for the perceived control subscale of the AFS, suggesting a non-linear relationship.

Finally, interaction effects between the quadratic term of self-transcendence and task type emerged as the strongest effects. They were significant for nine dependent variables and marginally significant for one more. The coefficients suggest that the pattern of the difference in scores follows a similar pattern for all the indicators.
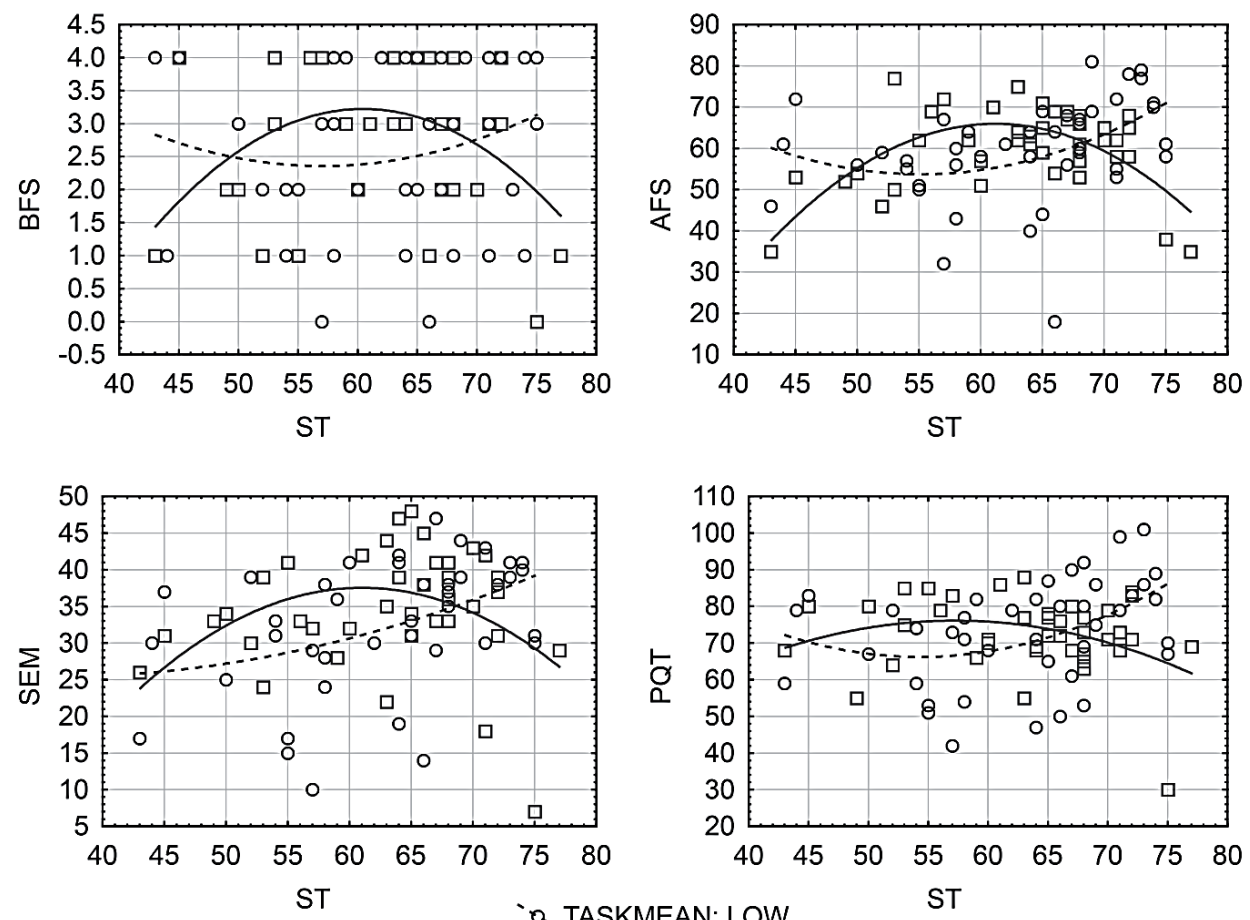

a. TASKMEAN: LOW

Note: ST - Self-Transcendence, BFS - Brief Flow Scale, AFS — Activity Flow Scale, SEM - Situational Experienced Meaning, PQT - Perceived Quality of Time.

Figure 1. Fit of the quadratic functions in the low-meaning and high-meaning conditions.

Simple effects analyses indicate that in the low-meaning condition self-transcendence was positively associated with overall flow, clarity of goals, perceived balance of challenges and skills, experienced meaning, and perceived quality of time. In all of these cases the fit of the quadratic model was significantly better than 
the fit of the linear model, but the differences in explained variance were rather small $\left(\Delta \mathrm{R}^{2}<.1\right)$. In contrast, in the high-meaning condition, linear function fit well only for the altered sense of time and freedom from social evaluation subscales of the AFS. For the BFS, total AFS score, clarity of goals, concentration, perceived control, and subjective experience of meaning this association had a pronounced inverted $U$ shape. The absolute differences between the variance explained by the quadratic and the linear model were also considerable $\left(\Delta \mathrm{R}^{2}>.1\right)$.

The fit of the resulting functions is shown inn Figure 1. The uniform pattern, which replicates across different measures, indicates that under the low-meaning condition, self-transcendence has a weak, positive, and mostly linear relationship to the experiential outcomes. However, under the high-meaning condition, this effect is clearly non-linear, suggesting that individuals with high self-transcendence scores tend to drop out of the "flow channel".

\section{Discussion}

We used a group creative task with two levels of situational meaning, which was operationalized as the presence of a given relationship of an activity to the participants' lives. In the low-meaning condition, the task was framed as an abstract one, a practice task on group creativity. In the high-meaning condition, the task was presented as related to the larger context of each participant's life, with its results having a potential practical value for society.

The meaning manipulation itself did not have a pronounced effect on the retrospective evaluations of the resulting experience. Participants under both conditions, on average, perceived the situation as somewhat meaningful and experienced similar levels of flow. The learning context and the creative nature of the task may have contributed to its perception as meaningful and enjoyable under both conditions. Another possible explanation for the absence of the effect of task on flow is that flow is a positive emotional phenomenon, whereas the task consisted in preventing a potential threat. Hence, its meaning would be subjectively reflected in negative emotions, which could interfere to some extent with the positive valence of flow.

We did not find any significant differences in the number of creative solutions produced for the social problem under the two conditions. However, the strongly significant differences between the qualities of the resulting solutions indicate that under the low-meaning condition, students tended to come up with creative, but abstract solutions, difficult to implement in practice. Under the high-meaning condition, students tended to come up with more realistic and potentially more useful ideas. This finding is in line with Leontiev's (2013) position that meaning is not an emotional experience, but a regulatory process that can have effects on cognition.

The findings of this pilot experimental study suggest that self-transcendence as a personality disposition is associated with task engagement, experienced task meaning, and flow. However, these associations have different shapes in the two situations: under the low-meaning task condition, self-transcendence showed a linear relationship to these outcomes, but under the high-meaning condition, this relationship was curvilinear. This suggests that the positive effects of self-transcendence may be more evident in uncertain settings, where tasks have no given meaning and the latter is to be discovered or created by the person. This is in line with 
the existential understanding of self-transcendence as the ability to relate to and to become motivated by values.

Out of the four dispositions measured by the Existence Scale, self-transcendence had the strongest correlations with flow indicators and was also the only scale to exhibit significant interaction effects with the experimental manipulation.

However, the results suggest that in situations of highly meaningful activities associated with solving real-life problems, very high levels of self-transcendence may result in over-engagement and suboptimal experience (whether this applies to tasks in general or only to tasks with negative meaning is yet to be investigated). The general pattern of a linear association in the low-meaning condition and quadratic association in the high-meaning condition is reminiscent of the findings of Abuhamdeh and Csikszentmihalyi (2009), which suggests that a combination of high intrinsic motivation orientation and high challenge may be detrimental to flow. This non-linearity may underlie the low correlation between self-transcendence and flow that Teng (2011) observed at the dispositional level.

\section{Limitations}

The non-linear associations of self-transcendence with the characteristics of subjective experience under high-meaning conditions have to be replicated in more controlled experimental settings. Because self-transcendence is a complex construct, future studies of these associations need to control for related constructs, such as extraversion or intrinsic motivational orientation, that could serve as potential confounds.

One limitation of the study was the absence of proper randomization at the small-group level. Although there were no significant differences in any of the measured personality characteristics between the participants under the two experimental conditions, the fact that the students worked in self-formed groups may have influenced the outcomes.

Another limitation was that operationalization of task meaning as its relation to the participants' home country may invoke potential confounds, such as practical knowledge and information availability, which could have influenced the qualitative characteristics of the resulting solutions.

\section{Conclusion}

The findings of the pilot study suggest that self-transcendence is a personality disposition that influences the way people engage with tasks. The results support the existential idea that self-transcendence helps to discover meaning, especially in situations when it is not readily available. However, high levels of self-transcendence may undermine optimal engagement and flow in highly meaningful situations.

A potential future research avenue is to find out whether the associations of objective task characteristics and self-transcendence with the resulting flow experience are indeed mediated by perceived meaning of the task. Are self-transcendent individuals more likely to see any task as meaningful, because they engage in meaning-making and actively relate the content of their task to some larger context of their lives? 
Future studies could investigate the differences in the effects of tasks with meaning reflected in positive and negative affect (activating approach and avoidance motives, respectively). Different aspects of task meaning, personal (the relation of the task to the context of individual life and personality) and social (its relation to the context of society at large) could also be isolated. Finally, future studies could investigate the effects of self-transcendence on meaning-making in unstructured and truly meaningless situations, more representative of real life than a structured and predictable university seminar is.

We call for more research linking flow theory and existential approach, using academic tools to clarify the nature and content of existential constructs, which could benefit future research and theorizing.

\section{Acknowledgments}

The study has been funded by the Russian Academic Excellence Project '5-100'. The authors are grateful to Ken Sheldon and Mike Prentice for their advice and to the anonymous reviewers for their useful comments on an earlier draft of the paper.

\section{References}

Abuhamdeh, S., \& Csikszentmihalyi, M. (2009). Intrinsic and extrinsic motivational orientations in the competitive context: An examination of person-situation interactions. Journal of Personality, 77(5), 1615-1635. http://dx.doi.org/10.1111/j.1467-6494.2009.00594.x

Bassi, M., Steca, P., Delle Fave, A., \& Caprara, G. V. (2007). Academic self-efficacy beliefs and quality of experience in learning . Journal of Youth and Adolescence, 36, 301-312. http:// dx.doi.org/10.1007/s10964-006-9069-y

Cloninger, C. R. (1987). A systematic method for clinical description and classification of personality variants. Archives of General Psychiatry, 44, 573-588. http://dx.doi.org/10.1001/ archpsyc.1987.01800180093014

Collins, A. L., Sarkisian, N., \& Winner, E. (2009). Flow and happiness in later life: An investigation into the role of daily and weekly flow experiences. Journal of Happiness Studies, 10, 703-719. http://dx.doi.org/10.1007/s10902-008-9116-3

Csikszentmihalyi, M. (1990). Flow: The Psychology of Optimal Experience. New York: Harper \& Row.

Csikszentmihalyi, M. (1997). Finding Flow. New York: Basic Books.

Csikszentmihalyi, M., Nakamura, J. (2003). The construction of meaning through vital engagement. In: C. L. M. Keyes \& J. Haidt (Eds.), Flourishing: Positive Psychology and the Life WellLived (pp. 83-104). Washington, DC: APA, 2003.

Delle Fave, A. (2013). Past, present and future of flow. In: S. A. David, I. Boniwell, \& A. Conley Ayers (Eds.), Oxford Handbook of Happiness (pp. 60-72). Oxford, UK: Oxford University Press. http://dx.doi.org/10.1093/oxfordhb/9780199557257.013.0005

Eisenberger, R., Jones, J. R., Stinglhamber, F., Shanock, L., \& Randall, A. T. (2005). Flow experiences at work: For high need achievers alone? Journal of Organizational Behavior, 26, 755-775. http://dx.doi.org/10.1002/job.337

Engeser, S., \& Rheinberg, F. (2008). Flow, performance and moderators of challenge-skill balance. Motivation and Emotion, 32, 158-172. http://dx.doi.org/10.1007/s11031-008-9102-4

Frankl, V. (1992). Man's Search for Meaning: An Introduction to Logotherapy. $4^{\text {th }}$ Ed. Boston, MA: Beacon Press. (Original work published 1959) 
Frankl, V. (1966). Self-transcendence as a human phenomenon. Journal of Humanistic Psychology, 6, 97-106. http://dx.doi.org/10.1177/002216786600600201

Garcia-Romeu, A. (2010). Self-transcendence as a measurable transpersonal construct. The Journal of Transpersonal Psychology, 42, 26-47.

Keller, J., \& Bless, H. (2008). Flow and regulatory compatibility: An experimental approach to the flow model of intrinsic motivation. Personality and Social Psychology Bulletin, 34, 196209. http://dx.doi.org/10.1177/0146167207310026

Keller, J., \& Blomann, F. (2008). Locus of control and the flow experience: An experimental analysis . European Journal of Personality, 22, 1-19. http://dx.doi.org/10.1002/per.692

Längle, A., Orgler, C., \& Kundi, M. (2003). The Existence Scale: A new approach to assess the ability to find personal meaning in life and to reach existential fulfillment. European Psychotherapy, 4, 135-151.

Leontiev, D. A. (2013). Personal meaning: A challenge for psychology. The Journal of Positive Psychology, 8, 459-470. http://dx.doi.org/10.1080/17439760.2013.830767

Mainina, I.N. (2009). Adaptaciya oprosnika Skala Eksistencii (Existenzskala; ESK) k russkoyazychnoi vyborke [Adaptation of the Existence Scale Test (Existenzskala; ESK) in a Russianspeaking sample]. Ekzistencialnyi Analiz [Existential Analysis], 1, 171-180.

Maslow, A. H. (1971). The Farther Reaches of Human Nature. New York: Viking.

May, R. (1958). Contributions of existential therapy. In: R. May, E. Angel, H. F. Ellenbrger (Eds.), Existence: A New Dimension in Psychiatry and Psychology (pp. 37-91). N. Y.: Basic Books. http://dx.doi.org/10.1037/11321-002

Moller, A. C., Meier, B. P., \& Wall, R. D. (2010). Developing an experimental induction of flow: Effortless action in the lab. In: B. Bruya (Ed.), Effortless Attention: A New Perspective in the Cognitive Science of Attention and Action (pp. 191-204). Cambridge, UK: MIT Press. http:// dx.doi.org/10.7551/mitpress/9780262013840.003.0010

Nakamura, J., \& Csikszentmihalyi, M. (2000). The concept of flow. In: C. R. Snyder \& S. J. Lopez (Eds.), Handbook of Positive Psychology (pp. 89-105). New York: Oxford University Press.

Payne, B. R., Jackson, J. J., Noh, S. R., \& Stine-Morrow, E. A. (2011). In the zone: Flow state and cognition in older adults. Psychology and Aging, 26, 738-743. http://dx.doi.org/10.1037/ a0022359

Reed, P. G. (1991). Self-transcendence and mental health in oldest-old adults. Nursing Research, 40, 5-11. http://dx.doi.org/10.1097/00006199-199101000-00002

Schmidt, J., Shernoff, D., \& Csikszentmihalyi, M. (2007). Individual and situational factors related to the experience of flow in adolescence: A multilevel approach. In: A. D. Ong \& M. van Dulmen (Eds.), The Handbook of Methods in Positive Psychology (pp. 542-558). Oxford, UK: Oxford University Press.

Teng, C.-I. (2011). Who are likely to experience flow?: Impact of temperament and character on flow. Personality and Individual Differences, 50, 863-868. http://dx.doi.org/10.1016/j. paid.2011.01.012

Walker, C. J. (2010). Experiencing flow: Is doing it together better than doing it alone? The Journal of Positive Psychology, 5, 3-11. http://dx.doi.org/10.1080/17439760903271116 


\section{Appendix}

\section{Text of the instruction leaflets}

\section{Low-meaning condition}

Dear colleagues:

We are asking you to take part in a brief creative task and to participate, as young experts, in the solution of a rather serious social problem.

In most countries of the world, employees of state law enforcement agencies (such as police officers) are permitted to carry and use firearms. However, in African countries this often leads to firearm abuse. During their off-work hours, police officers go on using their weapons, often for criminal purposes. Innocent civilians become their victims. The governments of African countries are trying to develop different strategies to solve this problem. We are asking you to use your knowledge of psychology to propose some ideas regarding possible measures to prevent firearm abuse among police officers in African countries.

We are asking you to work for 15 to 20 minutes in small groups, in order to come up with your ideas and write them down in a list. The more ideas you can suggest, the better. There are no limitations, but please remember that the measures have to be realistic enough to be implemented.

\section{High-meaning condition}

Dear colleagues:

We are asking you to take part in a brief creative task and to participate, as young experts, in the solution of a rather serious social problem.

You may be aware that in our country there have been cases of firearm abuse by employees of state law enforcement agencies (such as police officers). One recent example was the affair of Major Denis Evsyukov, who came with his pistol to a supermarket in Moscow, where he shot two people and wounded seven more. His victims were regular supermarket customers, and each of us could have been in their position. A number of cases like this take place every year, and the Ministry of Interior Affairs is looking for ways to change the situation, turning for advice to different experts, including psychologists. We are asking you to use your knowledge of psychology to propose some ideas regarding possible measures to prevent firearm abuse among police officers. Your ideas could potentially save someone's life.

We are asking you to work for 15 to 20 minutes in small groups, in order to come up with your ideas and write them down in a list. The more ideas you can suggest, the better. There are no limitations, but please remember that the measures have to be realistic enough to be implemented. 